\title{
Determinants of Food Security status in Rural Households in Mojaena Wodera Woreda, Ethiopia
}

\author{
Ayele Admasu \\ Department of Statistics, Debre Berhan University, Debre Berhan, Ethiopia \\ Email address: \\ bestayu.2002@gmail.com \\ To cite this article: \\ Ayele Admasu. Determinants of Food Security status in Rural Households in Mojaena Wodera Woreda, Ethiopia. American Journal of \\ Theoretical and Applied Statistics. Vol. 8, No. 2, 2019, pp. 67-76. doi: 10.11648/j.ajtas.20190802.13
}

Received: April 27, 2019; Accepted: June 2, 2019; Published: June 13, 2019

\begin{abstract}
The main objective of this study was to assess household food security status and its major determinants in the rural households of Mojaena Wodera Woreda, Ethiopia. A systematic random sampling method was employed to select the sample from study area. The study period was from September 2017 to September 2018. The recommended daily calorie requirement was used to determine the household food security status. To analyze the data descriptive statistics, bivariate analysis and both Classical logistic regression and Bayesian logistic regression analyses were used. The descriptive analysis of the study revealed that only $37.6 \%$ of the sample households were food secured and $62.4 \%$ of households were food insecured which was felt short of the $2100 \mathrm{kcal}$ per day per person that was national recommended calorie requirements. Based on Hosmer and Lemeshow test the chi-square value and significance value shows that Classical logistic model is quite a good fit. In addition to this, the classification results revealed that $81.3 \%$ of the households were correctly predicted Using both Classical and Bayesian logistic regression analysis, eight out of twenty-one predictor variables were selected as major determinants of household food security status. These significant variables were age, marital status, farm land size, land fertility, annual yield, improved seed use, having oxen and family size of household head. Government and the woreda agricultural office should provide cultivable and more fertile farm land, improved seed and support oxen to the farming households at affordable prices to be able to increase farmland size and total annual yield or food production.
\end{abstract}

Keywords: Household, Food Security Status, Classical Logistic Regression, Bayesian Logistic Regression

\section{Introduction}

Background of the study

Food insecurity is one of the most bedeviling issues and among the most challenging socio-economic problems for many countries in the world today, particularly the developing economies [1]. Food insecurity status is increasing from time to time. According to recent estimates of FAO over 870 million people are chronically malnourished and food insecure around the world [2]. Even though considerable efforts were made to reduce food insecurity, the number of people suffering from malnutrition and hunger remains unacceptably high. In the developing countries, the vast majority, over 850 million people, are estimated to be undernourished. The problem of food insecurity is not only caused by insufficient supply of food, but also due to the lack of purchasing power and access at national and household levels. The predominance of rain-fed agriculture in much of the developing world especially in sub-
Saharan African (SSA) has resulted in food systems that are highly reliant and sensitive to rainfall variability. Agricultural shocks, driven by climate changes, affect agricultural production and hence food security in a multitude of ways. Of the developing world, SSA appears to be the hardest area to food security risks. Several factors contributing to this insecurity in the region were identified and listed poor agricultural productivity as the major factor [3]. Agricultural productivity is constrained by poor technology, poor infrastructure, natural and man-made shocks, poor marketing, etc.

Ethiopia is one of the poorest countries in the world with worst scenario of poverty and food insecurity. Close to quarter of the population in Ethiopia in malnourished with largest proportion suffering from chronic hunger. The country has been structurally food deficit over the last decades [4]. In 2006, an estimated of 15 million rural people were food insecure while in 2012, an estimated 3.2 million 
people were reportedly food insecure, down from a peak of 4.5 million during the year 2011 [5].

In spite of the rapid and impressive progress in tackling poverty in recent years, it has been reported in subsequent food security assessment studies that on average nearly $35 \%$ of Ethiopians have been suffering from chronic food insecurity and undernourishment every year mainly caused by agricultural shocks and climate changes $[6,7]$. Several studies indicated that, $41 \%$ of the Ethiopian population lives below the poverty line and 31.6 million people are undernourished. The latest undernourishment numbers show a positive trend (1990-92: 71\% of the population; 1995-97: 64\%; 2000-02: 50\%; 2004-06: 44\%) [4]. Different factors were identified in various studies that aggravate food insecurity problem in Ethiopia. These are: poor soil fertility, land shortage, occasional droughts, and degradation of farm lands, frost attack, and chronic shortage of cash income, poor farming technologies, weak extension services, high labor wastage, and poor social and infrastructural situation. The combinations of those factors have resulted in serious and growing problem of household level food insecurity in Ethiopia [8]. Ethiopia is the most drought prone country in sub-Sahara Africa, and faced some severe famine catastrophes [9]. Food security situation in Ethiopia is highly linked up to severe, recurring food shortage and famine, which are associated to recurrent drought. Currently there is a growing consensus that food insecurity and poverty problems closely related in the Ethiopian context. More than 50 percent of the total population, of whom the majority reside in rural areas, does not have access to the medically recommended minimum average daily intake of 2100 calorie per person per day [10].

The study area Mojaena Wodera Woreda is one of the fertile Woreda of north Showa Zone. Rate of population growth is increasing due to lack of knowledge on family planning services on the part of the household head, limited health related service providers and socio-cultural influence as required in the woreda. Although the seriousness of food shortage varied from year to year, farm households faced seasonal food shortage almost every year. Food insecure and food secure farm households reside as neighbors and could share common climate and weather situation and mainly similar socio-economic, cultural and land topography. Yet, one faces seasonal food crisis and become dependent on food aid, while the other remains food secure, requiring no food aid. Recent literature discovered that even in years of adequate rainfall and good harvest, the households in the study area remain in need of food assistance. This clearly reflects the deeply entrenched poverty and transitory situation of the area irrespective of adequate rainfall. Although drought plays a paramount role in generating food crisis, the difference in consumption status of farm households between good year and bad year is not so significant to claim that drought is central cause of famine or transitory food insecurity. This implies the existence of structural, socio-economic, cultural, demographic and other factors underlying the poverty and seasonal food insecurity problem in the study area.

The general objective of this study is to assess household food security status and its major determinants in the rural households of Mojaena Wodera Woreda.

Accordingly, the central research questions of this study: what factorial differences make one household food secure and the other food insecure? What is the food production capacity and food security status of the rural households? How do factors such as socio- demographic, economic resource use, agricultural technologies and other natural factors influence food production and food security status of the households? Therefore, this study focused on determinants of Food Security Status in the Rural Households in Mojaena Wodera Woreda, Ethiopia.

\section{Methodology}

\subsection{Data Source}

Data obtained through administered questionnaire and data from agricultural office of the Mojaena Wodera Woreda and Ethiopian socio-economic survey of 2011/12 and 2013/14 data, collected by CSA of Ethiopia in collaboration with the World Bank.

\subsection{Target Population and Sampling Technique}

The target populations for this study were all rural Households those have farmland security tuner and farm land taxpayers in the Mojaena Wodera Woreda from period September 2017 to September 2018. The total populations of 17,381 farmland taxpayer households head were the population of the study area. To have a full picture of the district, a total of seven kebeles located at different places were selected purposely by the district-level experts after thorough discussion on the topic of the research. Besides, food insecurity status and access to irrigation facilities were also used as criteria for selecting the kebeles. List of households living in each of the selected kebeles was taken as a sampling frame, and then respondents selected using systematic random sampling technique proportionate to the size of households living in each kebele [11].

\section{Sample Size Determination}

In the determination of the sample size, a 95\% confidence level and a $p$ value of 0.05 for maximum variability were assumed. A simplified formula for proportions which is used to calculate Sample size adopted in this study was as follows [12].

$$
n=\frac{\mathrm{N}}{1+\mathrm{N}(e)^{2}}
$$

Where $\mathrm{n}$ is the sample size, $\mathrm{N}$ is the total population of farmland taxpayer of households head in all the selected kebeles and e designates maximum variability which is $5 \%$ (0.05), and 1 stands for probability of the event. The sample size was calculated, which resulted in a total of 391 participants (103 female and 288 male-headed households).

\subsection{Variables in the Study}

The dependent and independent variables that considered 
affecting the status of household food security status selected based on experiences from the available similar studies and the available data on the subject.

\subsubsection{The Dependent Variable}

Response variable for this study is Household Food Security Status (HFSS). It categorized as food secured and food insecure $[13,14]$.

A household whose daily per capita caloric available (supply) is less than his/her demand was regarded as food insecure (failure) and coded as 0 , while a household who did not experience a calorie deficit during the year under study was regarded as food secure (success) and was assigned a code of 1 .

In view of this, the response variable, household food security status of the $i^{\text {th }}$ household head, HFSS (Yi) measured as a dichotomous variable:

$$
Y_{i}=\left\{\begin{array}{l}
1, \text { if the } \dot{1}^{\text {th }} \text { household head is food secured } \\
0, \text { if the } \dot{1}^{\text {th }} \text { household head is food insecured }
\end{array}\right.
$$

Where $\mathrm{Y}_{\mathrm{i}}$, is household food security status (HFSS) of the $i^{\text {th }}$ household head, $i=1,2,3, \ldots, 391$.

\subsubsection{Independent Variables}

The explanatory variables measured as continuous and discrete (categorical) variables identified to be major determinants of household food security in this study. The independent variables grouped under different classes such as socio- demographic Variables (Sex, age, household size, education level, marital status), Economic Resource Variables (annual yield, land size, number of oxen, off-farm, labor force, tropical livestock unit (TLU)), Agricultural Technology Use Variables (chemical fertilizer, improved seed, access to irrigation, access to irrigation, farm credit) and other variables (food aid, agricultural inputs, land fertility, availability of rain, land topography, topography influence).

\subsection{Methods of Statistical Analysis}

For this study both descriptive statistics (like frequency distribution, Descriptive Summary Statistics) and inferential statistics (like Bivariate Analysis, chi-square test, likelihood ratio (LR) tests, logistic regression model and Bayesian Logistic Regression Model were used to make inference or conclusion about the population based on sample taken from the population.

\section{Classical Logistic Regression Model}

The model for logistic regression analysis assumes that the dependent variable is categorical.The dependent variable was household food security status; the household head with food secured (1) and household head with food insecured (0). The model given in (1) is logistic regression model.

$$
\mathrm{P}_{\mathrm{i}}=\frac{\exp \left(\beta_{0}+\beta_{1} x_{i 1}+\cdots+\beta_{p} x_{i p}\right)}{1+\exp \left(\beta_{0}+\beta_{1} x_{i 1}+\cdots+\beta_{p} x_{i p}\right)}=\frac{\exp \left(X_{i}^{\prime} \beta\right)}{1+\exp \left(X_{i}^{\prime} \beta\right)}
$$

The ratio of the two probabilities $\frac{P i}{1-P i}$ is the odds that the household head with food secured.
In terms of odds the logistic regression model can be written as:

$$
\frac{P i}{1-P i}=\exp \left(\beta_{0}+\beta_{1} x_{i 1}+\cdots+\beta_{p} x_{i p}\right) \quad \text {. The logit }
$$

transformation of $\mathrm{P}_{\mathrm{i}}$ given as follows:

$$
\log i t\left[P_{i}\right]=\log \frac{P_{i}}{1-P_{i}}=\beta_{o}+\beta_{1} X_{i 1}+\ldots .+\beta_{p} X_{i p}
$$

\subsection{Bayesian Inference for Logistic Regression Parameters}

The basic concepts that are considered in Bayesian analysis are a prior distribution over all unknown parameters, the likelihood function of the data and the posterior distribution over all parameters. It is concerned with generating the posterior distribution of the unknown parameters given both the data and some prior density for the unknown parameters. Bayesian inference for logistic analyses follows the usual pattern for all Bayesian analyses:

1. Form a prior distribution over the space of all unknown parameters.

2. Write down the likelihood function of the data.

3. Use Baye's theorem to find the posterior distribution over all parameter spaces.

If $\beta$ is a random variable with probability density function $f(\beta)$ and likelihood function $f($ data $\mid \beta)$, then according to Baye's theorem, the posterior distribution function can be written generally as:

$$
f(\beta \mid \text { data })=\frac{f(\text { data } \mid \beta) \times f(\beta)}{f(\text { data })} \propto \text { likelihood } \times \text { prior }
$$

Where $f(\beta)$ is the prior distribution of the unknown parameter.

\subsubsection{Prior Distribution}

The choice can include informative prior distributions if something is known about the likely values of the unknown parameters $\beta=\left(\beta_{0}, \beta_{1}, \ldots, \beta p\right)^{\prime}$ or non-informative priors if either little is known about the coefficient values or if one wishes to see what the data themselves provide as inferences. If informative prior distributions are desired, it is often difficult to give such information on the logit scales, that is, on the unknown $\beta$ parameters directly. For this study, we use the most common priors for logistic regression parameters, which is a normal distribution with mean $\mu$ and variance $\sigma^{2}$. The most common choice for $\mu$ is zero, and $\sigma^{2}$ is usually chosen to be large enough to be considered as noninformative, common choices being in the range from $\sigma^{2}=$ 10 to $\sigma^{2}=100[15]$.

Thus, the assumed prior normal distribution for parameter $\beta_{j}$ is given by

$$
f\left(\beta_{j}\right)=\frac{1}{\sqrt{2 \pi} \sigma_{j}} \exp \left\{\frac{-1}{2}\left(\frac{\beta_{j}-\mu_{j}}{\sigma_{j}}\right)^{2}\right\}
$$

\subsubsection{Likelihood Function}

The joint distribution of $\mathrm{n}$ independent Bernoulli trials is 
the product of the individual probability densities. A Binomial distribution is the sum of $n$ independent and identically distributed Bernoulli trials. Specifically, let $\mathrm{Y}_{1}$, $\mathrm{Y}_{2, \ldots} \ldots, \mathrm{Y}_{\mathrm{n}}$ be independent Bernoulli random variables with success probabilities $\mathrm{P}_{1}, \mathrm{P}_{2}, \mathrm{P}_{3}, \ldots, \mathrm{Pn}$, that is, $\mathrm{Y}_{\mathrm{i}}=1$ with probability $\mathrm{P}_{\mathrm{i}}$ or $\mathrm{Yi}=0$ with probability $1-\mathrm{P}_{\mathrm{i}}$, for $\mathrm{i}=1,2, \ldots, \mathrm{n}$. Since the trials are independent, the joint distribution of $Y_{1, \ldots,} Y_{n}$ is the product of $n$ Bernoulli probabilities. Let $Y_{n x 1}$ be a dichotomous outcome random variable with categories 1 (household head with food secured) and 0 (household head with food insecured). Let $X_{n x(p+1)}$ denote the collection of ppredictor variables of $\mathrm{Y}$, where:

$$
\begin{aligned}
& \mathrm{X}=\left[\begin{array}{cccccc}
1 & x_{11} & x_{12} & x_{13}, \ldots \ldots & x_{1 p} \\
1 & x_{21} & x_{22} & x_{23}, \ldots \ldots & x_{2 p} \\
\ldots \ldots \ldots \ldots \ldots \ldots \ldots \ldots & \ldots \ldots \ldots \\
1 & x_{n 1} & x_{n 2} & x_{n 3}, \ldots \ldots & x_{n p}
\end{array}\right] \\
& L(\beta \mid y)=\prod_{i=1}^{n}\left(\frac{e^{\beta_{o}+\beta_{1} x_{i 1}+\ldots+\beta_{p} x_{i p}}}{1+e^{\beta_{o}+\beta_{1} x_{i 1}+\ldots+\beta_{p} x_{i p}}}\right)^{y_{i}}\left(1-\frac{e^{\beta_{o}+\beta_{1} x_{i 1}+\ldots+\beta_{p} x_{i p}}}{1+e^{\beta_{o}+\beta_{1} x_{i 1}+\ldots .+\beta_{p} x_{i p}}}\right)^{\left(1-y_{i}\right)}
\end{aligned}
$$

\subsubsection{Posterior Distribution}

The posterior distribution is derived by multiplying the prior distribution over all parameters by the full likelihood function. We can write the posterior distribution as follows:

$$
f(\boldsymbol{\beta} \mid \boldsymbol{y}, \boldsymbol{X})=\left[\prod_{i=1}^{n}\left(\left(\frac{e^{Z}}{1+e^{Z}}\right)^{y_{i}}\left(1-\frac{e^{Z}}{1+e^{Z}}\right)^{1-y_{i}}\right) \times \prod_{j=0}^{p} \frac{1}{\sqrt{2 \pi} \delta_{j}} \exp \left(-\frac{1}{2}\left(\frac{\beta_{j}-\mu_{j}}{\delta_{j}}\right)^{2}\right)\right]
$$

where $\mathrm{z}=\beta_{0}+\beta_{1} x_{i 1}+\cdots+\beta_{p} x_{i p}, \beta_{0}$ is the constant term and $\beta_{j}$ 's are the coefficients of predictor variables $x_{i j}$.

\subsubsection{Markov Chain Monte Carlo (MCMC) Methods}

Suppose that we partition the parameter vector of interest

$$
\left\{\prod\left(\beta_{1} \mid \beta_{2}, \beta_{3}, \ldots, \beta_{p}\right), \prod\left(\beta_{2} \mid\left(\beta_{1}, \beta_{3}, \ldots,\left(\beta_{p}\right), \ldots, \Pi\left(\beta_{p} \mid \beta_{1}, \beta_{2}, \ldots, \beta_{p-1}\right)\right\}\right.\right.
$$

It is essential that there is a definable conditional statement for each coefficient in the $\beta$ vector and the probability statements are completely articulated so that it is possible to draw samples from the described distribution. The nuisance parameters are sampled given the parameters of interest and the observed data. The iterative procedure of the Gibbs sampling algorithm is outlined below:

Give initial value $\beta^{(0)}=\left(\beta_{0}^{(0)}, \beta_{1}^{(0)}, \ldots, \beta_{p}^{(0)}\right)$.

Repeat for $\mathrm{j}=0,1,2, \ldots, \mathrm{M}-1$.

Generate $\beta_{0}^{j+1}$ from $\pi\left(\beta_{0} \| \beta_{1}^{(j)}, \beta_{2}^{(j)}, \ldots, \beta_{p}^{(j)}\right)$.

Generate $\beta_{1}^{j+1}$ from $\pi\left(\beta_{1}|| \beta_{0}^{(j+1)}, \beta_{2}^{(j)}, \ldots, \beta_{p}^{(j)}\right)$. into $\mathrm{p}$-components $\beta^{\prime}=\left(\beta_{1}, \beta_{2}, \beta_{3} \ldots \beta_{\mathrm{p}}\right)$. The Gibbs sampler algorithm is implemented by sampling the set of full conditional distributions from the p-conditional posterior distributions is as follows [16].

Generate $\beta_{p}^{j+1}$ from $\pi\left(\beta_{p}|| \beta_{0}^{(j+1)}, \beta_{1}^{(j+1)}, \ldots, \beta_{p-1}^{(j+1)}\right)$.

Repeat step 2 until convergence.

Return the values $\left(\beta^{1}, \beta^{2}, \ldots, \beta^{M}\right)$

\section{Results and Discussions}

\subsection{Descriptive Statistics Results}

This section reports the descriptive results of the relationship between household food security status and its determinants. The sample sizes determined for this study was 391. So, the data analyzed with a sample of 391 respondents.

Table 1. Descriptive Summary Statistics of Continuous Independent Variables.

\begin{tabular}{lllll}
\hline Descriptive Statistics & & & & \\
\hline Continuous variables & N & Minimum & Maximum & Mean \\
\hline Age of HHs head (in yrs) & 391 & 19.00 & 79.00 & 46.73 \\
Farm land size of HHs (in hectare) & 391 & 0.25 & 12.75 & 4.82 \\
Annual yield (in quintal) & 391 & 1.50 & 99.00 & 27.14 \\
Tropical livestock unit (TLU) & 391 & 0.00 & 87.61 & 17.90 \\
family size (in number) & 391 & 1.00 & 13.00 & 12.73 \\
\hline
\end{tabular}

Source: Own Source. 
As the result shows in Table1, the average age of household head (in year) was 46.73 and its standard deviation was 11.14. The farmland size of household (in hectare) was with mean 4.82 and standard deviation of 2.90 and its minimum and maximum was 0.25 and 12.75 respectively. The average annual yield (in quintal) was 27.35 and its standard deviation was 17.45 ; this result shows that there were high variations among households in their annual yield production. The number of livestock owned (in TLU) was with average and standard deviation of 12.73 and 12.80 , respectively. The average and standard deviation of family size were 6.88 and 2.91 and its minimum and maximum values were 1 and 13 respectively.

\subsection{Bivariate Analysis Results}

In this section, the association between the outcome variable household food security status and each predictor variables conducted by cross tabulating each predictor variables against the outcome variable, using chi-square and likelihood ratio (LR) tests.

Table 2. Association between Rural Household Food Security Status and Categorical Explanatory Variables.

\begin{tabular}{|c|c|c|c|c|c|c|c|}
\hline Variables & $\mathbf{N}$ & Total \% & Food secure\% & Food insecure\% & Pearson Chi-square & LR and Sig. & d. $f$ \\
\hline \multicolumn{8}{|l|}{ Gender } \\
\hline Female & 103 & 26.3 & 30.1 & 69.9 & 3.35 & 3.42 & \multirow{2}{*}{1} \\
\hline Male & 288 & 73.7 & 40.3 & 59.7 & $(0.067)$ & $(0.064)$ & \\
\hline \multicolumn{8}{|l|}{ Age of HHs head } \\
\hline$<30$ & 46 & 11.8 & 52.2 & 47.8 & \multirow{4}{*}{$\begin{array}{l}22.05 \\
(0.000)\end{array}$} & & \multirow{4}{*}{4} \\
\hline $30-39$ & 89 & 22.8 & 48.3 & 51.7 & & 23.56 & \\
\hline $50-59$ & 79 & 20.2 & 27.8 & 72.2 & & $(0.000)$ & \\
\hline$>=60$ & 43 & 11.0 & 14.0 & 86.0 & & & \\
\hline \multicolumn{8}{|l|}{ Marital status of HHs head } \\
\hline Single & 87 & 22.3 & 28.7 & 71.3 & 5.83 & 6.00 & \multirow{3}{*}{2} \\
\hline Married & 281 & 71.9 & 41.3 & 58.7 & $(0.050)$ & $*$ & \\
\hline Divorced/ Widowed & 23 & 5.9 & 26.1 & 73.9 & & $(0.050)$ & \\
\hline \multicolumn{8}{|c|}{ Educational level of $\mathrm{HHs}$ head } \\
\hline Can read and /or write & 128 & 32.7 & 38.3 & 61.7 & $(0.000)$ & $*$ & \multirow[t]{2}{*}{2} \\
\hline Primary school and above & 90 & 23.0 & 54.4 & 45.6 & & $(0.000)$ & \\
\hline \multicolumn{8}{|l|}{ Farm land size of HHs head } \\
\hline$<2$ hectare & 52 & 13.3 & 17.3 & 82.7 & \multirow{4}{*}{$\begin{array}{l}19.99 \\
(0.000)\end{array}$} & 20.83 & \multirow{4}{*}{3} \\
\hline$(2-5)$ hectare & 171 & 43.7 & 33.3 & 66.7 & & $(0.000) *$ & \\
\hline$(5-8)$ hectare & 97 & 24.8 & 44.3 & 55.7 & & & \\
\hline$>=8$ hectare & 71 & 18.2 & 53.5 & 46.5 & & & \\
\hline \multicolumn{8}{|l|}{ Farm land topography } \\
\hline Plain & 288 & 73.7 & 39.9 & 60.1 & 2.54 & 2.58 & \multirow{2}{*}{1} \\
\hline Not plain & 103 & 26.3 & 31.1 & 68.9 & $(0.111)$ & $(0.108)$ & \\
\hline \multicolumn{8}{|c|}{ Topography influence on production } \\
\hline Low & 184 & 47.1 & 40.8 & 59.2 & 1.49 & 1.49 & \multirow[b]{2}{*}{2} \\
\hline Medium & 169 & 43.2 & 34.9 & 65.1 & $(0.475)$ & $(0.475)$ & \\
\hline Less fertile & 46 & 11.8 & 21.7 & 78.3 & 15.13 & 15.31 & \multirow{3}{*}{2} \\
\hline Medium fertile & 208 & 53.2 & 33.2 & 66.8 & \multirow[t]{2}{*}{$(0.001)$} & $*$ & \\
\hline High fertile & 137 & 35.0 & 48.6 & 50.4 & & $(0.000)$ & \\
\hline \multicolumn{8}{|l|}{ Availability of rain } \\
\hline Too little & 59 & 15.1 & 33.9 & 66.1 & 2.86 & 2.81 & \\
\hline Enough & 263 & 67.3 & 36.1 & 63.9 & \multirow{2}{*}{$\begin{array}{l}2.86 \\
(0.240)\end{array}$} & $(0.246)$ & 2 \\
\hline Too much & 69 & 17.6 & 46.4 & 53.6 & & & \\
\hline Annual yield & & & & & & & \\
\hline$<27.35$ & 223 & 57.0 & 23.8 & 76.2 & 42.31 & 42.64 & \\
\hline$>=27.35$ & 168 & 43.0 & 56.0 & 44.0 & $(0.000)$ & $(0.000) *$ & 1 \\
\hline Participation in off-farm ac & & & & & & & \\
\hline Yes & 112 & 28.6 & 36.6 & 63.4 & 0.065 & 0.066 & \\
\hline No & 279 & 71.4 & 38.0 & 62.0 & $(0.798)$ & $(0.798)$ & 1 \\
\hline Chemical fertilizer use & & & & & & & \\
\hline Yes & 274 & 70.1 & 47.1 & 52.9 & 35.11 & 38.35 & \\
\hline No & 117 & 29.9 & 15.4 & 84.6 & $(0.000)$ & $(0.000) *$ & 1 \\
\hline Improved seed & & & & & & & \\
\hline
\end{tabular}




\begin{tabular}{|c|c|c|c|c|c|c|c|}
\hline Variables & $\mathbf{N}$ & Total \% & Food secure\% & Food insecure\% & Pearson Chi-square & LR and Sig. & d. $f$ \\
\hline Used & 265 & 67.8 & 52.8 & 47.2 & 81.35 & 97.14 & \multirow{2}{*}{1} \\
\hline Not used & 126 & 32.2 & 5.6 & 94.4 & $(0.000)$ & $(0.000) *$ & \\
\hline \multicolumn{8}{|c|}{ Farm credit use } \\
\hline Yes & 129 & 33.0 & 37.2 & 62.8 & 0.012 & 0.012 & \multirow{2}{*}{1} \\
\hline No & 262 & 67.0 & 37.8 & 62.2 & $(0.912)$ & $(0.912)$ & \\
\hline \multicolumn{8}{|c|}{ Access to irrigation water } \\
\hline Yes & 118 & 30.2 & 43.2 & 56.8 & 2.28 & 2.26 & \multirow{2}{*}{1} \\
\hline No & 273 & 69.8 & 35.2 & 64.8 & $(0.13)$ & $(0.13)$ & \\
\hline \multicolumn{8}{|c|}{ Tropical livestock unit (TLU) } \\
\hline$<12.73$ & 236 & 60.4 & 29.7 & 70.3 & 15.98 & 15.89 & \multirow{2}{*}{1} \\
\hline$>=12.73$ & 155 & 39.6 & 49.7 & 50.3 & $(0.000)$ & $(0.000) *$ & \\
\hline \multicolumn{8}{|c|}{ Owner of an ox } \\
\hline Own ox & 295 & 75.4 & 47.5 & 52.5 & 49.81 & 59.39 & \multirow{2}{*}{1} \\
\hline Not own ox & 96 & 24.6 & 7.3 & 92.7 & $(0.000)$ & $(0.000) *$ & \\
\hline \multicolumn{8}{|c|}{ Attitude toward food aid } \\
\hline Positive & 184 & 47.1 & 31.5 & 68.5 & 5.47 & 5.49 & \multirow{2}{*}{1} \\
\hline Negative & 207 & 52.9 & 43.0 & 57.0 & $(0.019)$ & $(0.019) *$ & \\
\hline \multicolumn{8}{|c|}{ Enough labour force } \\
\hline Yes & 244 & 62.4 & 41.8 & 58.2 & 4.89 & 4.96 & \multirow{2}{*}{1} \\
\hline No & 147 & 37.6 & 30.6 & 69.4 & $(0.027) *$ & $(0.026)$ & \\
\hline \multicolumn{8}{|c|}{ Agricultural input distribution } \\
\hline Used & 66 & 16.9 & 28.8 & 71.2 & 2.63 & 2.71 & \multirow{2}{*}{1} \\
\hline Not used & 325 & 83.1 & 39.4 & 60.6 & $(0.105)$ & $(0.100)$ & \\
\hline \multicolumn{8}{|l|}{ Family size } \\
\hline$<=4$ & 84 & 21.5 & 40.5 & 59.5 & 3.08 & 3.13 & \\
\hline$(5-8)$ & 188 & 48.1 & 40.4 & 59.6 & $(0.045)$ & * & 2 \\
\hline$>=9$ & 119 & 30.4 & 31.1 & 68.9 & & $(0.042)$ & \\
\hline
\end{tabular}

Source: Own Source.

From the variables in the above Table (Table 2), The predictor variables, like age of household head, marital status of household head, educational level of household head, farm land size of household head, family size, land fertility, annual yield of household head, chemical fertilizer use, improved seed use, Attitude toward food aid, number of live stock owned, having oxen and having enough labor force were statistically significant variables using chi-square and likelihood ratio tests.

As we see in Table2 above, among 391 household head, $26.3 \%$ were female and $73.7 .3 \%$ were male. The proportion of food security is higher among households led by men $(40.3 \%)$. The proportion of being food secure in the age categories $<30,30-39,40-49,50-59$ and $>60$ were $52.2 \%$, $48.3 \%, 38.8 \%, 27.8 \%$ and $14.0 \%$, respectively; this shows that as the age of household head increases the probability of being food secured will decreases. The number of sampled household head with age categories 30-39 and 40-49 were $57.1 \%$; which covers more than half of the total. Therefore, the figure $34.3 \%$ of food secured depends on the sampled number of households. In the age category of $50-59$ and $>=$ 60 the proportion of being food insecure will be increased.

On the other hand being food secured is good as household head is educated. This indicates that better educated household heads are more likely to be food secured than those headed by uneducated household heads. The results in Table2, shows the household heads with education level of can't read and/or write, can read and/or write and primary school and above have the proportion of being food secured as $28.3 \%, 38.3 \%$ and $54.4 \%$ respectively.

In addition, this study shows as household head educational level increases from the category cannot read and/ or write to the primary school and above level the proportion of being food insecure were $71.7 \%, 61.7 \%$ and $45.6 \%$ respectively. While the proportion of being food insecure decreases as household head was educated; this indicates that households with relatively better-educated household heads are more likely to be food secure than those headed by uneducated household heads. The result in Table2 shows farm land size with categories $<2$ hectare, (2-5) hectare, (5-8) hectare and $>=8$ hectare of sampled household's proportion of being food secured were $17.3 \%$, $33.3 \%, 44.3 \%$ and $53.5 \%$. This shows that farmland size is one of the main factors that affect household food security status. One of the food security problems was farmland topography and farmland topography from the sampled rural households in the study was plain and not plain with the proportion $73.7 \%$ and $26.3 \%$ respectively.

Another important variable is the annual yield of the household head. As the result shows if the annual yield is less than the average value (27.35), the probability of being food insecure is about $76.2 \%$, which is large but if the annual yield is greater than the average value (27.35), the probability of being food secure is about $56.0 \%$. As the result shows if the number of livestock owned is less than the average value (12.73), the probability of being food secure is $29.7 \%$, but if the number of livestock owned is 
greater than the average value (12.73), the probability of being food secure is about $49.7 \%$. Also variables like, land fertility, chemical fertilizer used, improved seed use and having enough labor force were other factors which affects households' food security status.

\subsection{Multiple Logistic Regression Analysis}

Using the Forward Stepwise (Likelihood Ratio) method in SPSS, only eight out of twenty one predictor variables were selected by the model and they were statistically significant, like age of household head, marital status of household head, land size, land fertility, annual yield, improved seed used, being an owner of oxen and family size.

\subsubsection{Assessing Classical Logistic Regression Model}

The overall significance tested using what SPSS calls the Model Chi-square, which derived from the likelihood of observing the actual data under the assumption that the model fitted is accurate.

Table 3. Omnibus Tests of Model Coefficients.

\begin{tabular}{llll}
\hline \multicolumn{4}{l}{ Omnibus Tests of Model Coefficients } \\
\hline & Chi-square & df & Sig. \\
\hline Step & 9.167 & 1 & .002 \\
Block & 186.245 & 7 & .000 \\
Model & 186.245 & 7 & .000 \\
\hline
\end{tabular}

The result of omnibus tests of models coefficients had a chi-square value of 186.245 on 7 degrees of freedom, which was significant at level of significance, $\alpha=0.05$. This indicates that the improvement in fit of the full model.
Table 4. Model Summary.

\begin{tabular}{lll}
\hline Model Summary & & \\
\hline -2Log likelihood & Cox \& Snell R- Square & Nagelkerke R-Square \\
\hline 541.074 & .305 & .496 \\
\hline
\end{tabular}

The Model Summary provides some approximations of $\mathrm{R}^{2}$ statistic in logistic regression. In this study, Cox and Snell Rsquare indicate that $30.5 \%$ of the variation in the dependent variable, household food security status explained by its predictor variables. Nagelkerke's $\mathrm{R}^{2}$ in Model Summary of Table 4 shows that about $49.6 \%$ of the household food security status was explained by the explanatory variables using Nagelkerke R -square statistic.

Table 5. Hosmer and Lemeshow Test.

\begin{tabular}{lcl}
\hline Chi-square & Df & Sig. \\
\hline 9.900 & 8 & 0.272 \\
\hline
\end{tabular}

This desirable outcome of non-significance indicates that the model prediction does not significantly differ from the observed. Since p-value (0.272) exceeds 0.05 level of significance, that shows there is no difference between the observed and predicted model value and hence estimates of the model fit the data at level of an acceptance.

\subsubsection{Classification Table}

Rather than using a goodness-of-fit statistic, we often want to look at the proportion of cases we have managed to classify correctly. The overall accuracy of the model to predict subject's household food security status, in Table 6 shows that out of the 391-sample household head included in the model $81.3 \%$ correctly predicted.

Table 6. Classification Table.

\begin{tabular}{lllll}
\hline Classification Table & \multicolumn{3}{l}{ Predicted } & \\
\cline { 3 - 4 } \multirow{3}{*}{ Observed } & & Household Food Security Status & Percent \\
\cline { 3 - 4 } & & Food secure & 41 & 83.2 \\
Household Food Security status & Food secure & 203 & 115 & 78.2 \\
Overall Percent & 32 & & 81.3 & \\
\hline
\end{tabular}

The specificity given by $83.2 \%$ and the sensitivity given by $78.2 \%$, which indicate $83.2 \%$ of food secure and $78.2 \%$ of food insecure households correctly predicted in their respective categories.

Table 7. Variable in the final multiple logistic regression model for food security.

\begin{tabular}{|c|c|c|c|c|c|c|}
\hline \multicolumn{7}{|c|}{ Variables in the Equation } \\
\hline & $\boldsymbol{\beta}$ & 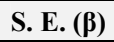 & Wald & df & Sig. & $\operatorname{Exp}(\beta)$ \\
\hline Age & & & $18.546^{*}$ & 4 & .001 & \\
\hline Age (1) & -1.815 & .505 & $12.934 *$ & 1 & .000 & .163 \\
\hline Age (2) & -1.505 & .425 & $12.517^{*}$ & 1 & .000 & .222 \\
\hline Age (3) & -1.187 & .396 & $8.993^{*}$ & 1 & .003 & .305 \\
\hline Age (4) & -.737 & .426 & 2.995 & 1 & .084 & .479 \\
\hline Marital status & & & $6.118^{*}$ & 2 & .047 & \\
\hline Marital status (1) & 1.149 & .540 & $4.529 *$ & 1 & .033 & 3.156 \\
\hline Marital status (2) & -.076 & .271 & .078 & 1 & .780 & .927 \\
\hline Land size & & & $9.097^{*}$ & 3 & .028 & \\
\hline Land size (1) & 1.329 & .528 & $6.327^{*}$ & 1 & .012 & 3.776 \\
\hline Land size (2) & .760 & .317 & $5.741^{*}$ & 1 & .017 & 2.139 \\
\hline Land size (3) & .243 & .312 & .609 & 1 & .435 & 1.276 \\
\hline
\end{tabular}




\begin{tabular}{|c|c|c|c|c|c|c|}
\hline \multicolumn{7}{|c|}{ Variables in the Equation } \\
\hline & $\boldsymbol{\beta}$ & 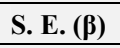 & Wald & df & Sig. & $\operatorname{Exp}(\beta)$ \\
\hline Land fertility & & & $6.782 *$ & 2 & .034 & \\
\hline Land fertility (1) & .844 & .380 & $4.940^{*}$ & 1 & .026 & 2.325 \\
\hline Land fertility (2) & .450 & .227 & $3.928^{*}$ & 1 & .047 & 1.568 \\
\hline Yield (1) & .868 & .253 & $11.823 *$ & 1 & .001 & 2.383 \\
\hline Imp.seed (1) & -1.611 & .259 & $38.598 *$ & 1 & .000 & .200 \\
\hline Have Oxen (1) & -1.352 & .343 & $15.527^{*}$ & 1 & .000 & .259 \\
\hline Family size & & & $22.153 *$ & 2 & .000 & \\
\hline Family size (1) & -1.845 & .395 & $21.827 *$ & 1 & .000 & .158 \\
\hline Family size (2) & -.820 & .270 & $9.219^{*}$ & 1 & .002 & .440 \\
\hline Constant & 3.416 & .597 & $32.798 *$ & 1 & .000 & 30.451 \\
\hline
\end{tabular}

*Statistically significant at $\mathrm{p}<0.05$

Using the Forward Stepwise (likelihood ratio) method in SPSS software, only eight predictor variables were selected by the model, like age of household head, marital status of household head, land size of household head, land fertility, total annual yield, improved seed used, being owner of oxen and family size. All of those eight variables selected by the model have significant effect on the outcome variable, household food security status. Note that the odds ratio interpretation of a given covariate is valid if and only if the remaining covariates are controlled or set fixed.

The first significant predictor variables that affects household food security status is age of a household head. This predictor has four categories and the last category (household head having Age $\geq 60$ ) was used as reference. As we see odds ratio interpretation of age categorized as $<30$, $30-39,40-49,50-59$ and $>=60$. The household head with age category $<30$ is about $83.7 \%$ more likely food secure than the reference category. The household having head with age category $30-39$ is about $77.8 \%$ more likely food secure than the reference category and the household having head with age category $40-49$ is about $69.5 \%$ more likely food secure than the reference age category. Therefore, the result shows that, as the age increased there was a decrease in the probability of being food secured.

Marital status of the household categorized as single, married and divorced/widowed. The first category (single) was used as reference. The result in the Table shows that the household with married head is about 3.156 times more likely food secure than the reference group. Households head with divorced/widowed were found to have a higher probability of becoming food insecure as compared to the reference category (single house hold head).

The farmland fertility categorized as high, medium and less fertile. The results in the Table 7 show, the households with high fertile farm land is about 2.325 times more likely food secure than the reference category (farmland with less fertile) and the households with medium fertile farm land is about $56.8 \%$ more likely food secured than the reference category (farmland with less fertile). Odds ratio of total annual yield indicates an increase in 1 quintal of cereals or grains increases 2.383 times being food secure. Households those used improved seed is about $80 \%$ more likely food secured than the reference category (who didn't used improved seed). Households those who have own oxen is about $74 \%$ more likely food secured than the reference category that have no own oxen. Another important variable for household food security status is family size, which is negatively related to the probability of being food secured that is as family size increase there is a decrease of probability of being food secured.

\subsection{Assessing Bayesian Logistic Regression Model}

To have accurate posterior estimates the simulation should be run until the Monte Carlo error for each parameter of interest is less than about $5 \%$ of its posterior standard deviation, and hence evidence for accuracy of posterior estimates in Bayesian logistic regression is accomplished. After, convergence and accuracy of posterior estimates attained and summarizing the posterior statistic is achievable.

Table 8. summary statistic of the posterior distribution of the model parameters.

\begin{tabular}{|c|c|c|c|c|c|}
\hline \multirow{2}{*}{ node } & \multirow{2}{*}{$\beta$} & \multirow{2}{*}{ SD } & \multirow{2}{*}{ MC error } & \multicolumn{2}{|l|}{$95 \%$ CI } \\
\hline & & & & Lower & Upper \\
\hline Constant & -1.6810 & 0.7600 & 0.021750 & -3.1860 & -0.1868 \\
\hline Age & -0.4087 & 0.1074 & 0.001049 & -0.6195 & -0.1971 \\
\hline Marital status & 0.5859 & 0.2405 & 0.003809 & 0.1200 & 1.0630 \\
\hline Land size & 0.4276 & 0.1626 & 0.002112 & 0.1082 & 0.7468 \\
\hline Land fertility & 0.4869 & 0.1838 & 0.002467 & 0.1286 & 0.8506 \\
\hline Annual yield & 0.7978 & 0.2756 & 0.002483 & 0.2575 & 1.3370 \\
\hline Improved seed used & -1.5070 & 0.3098 & 0.002002 & -2.1210 & -0.9079 \\
\hline Owner of oxen & -1.2780 & 0.3776 & 0.002566 & -2.0410 & -0.5590 \\
\hline Family size & -0.9300 & 0.2059 & 0.002329 & -1.3380 & -0.5322 \\
\hline
\end{tabular}


In Table 8, MC error for each significant predictor is less than $5 \%$ of its posterior standard deviation. This implies convergence and accuracy of posterior estimates attained and the model is appropriate to estimate posterior statistics. The predictors' given in the Table 8 , like age of household head, marital status of household, farm land size of household, farm land fertility, total annual yield, improved seed used, being owner of oxen and family size were statistically significant predictor variables. Because 95\% confidence intervals does not contains zero. This shows significant variables are more influencing factors of rural household food security status.

\subsection{Discussions}

This study tried to identify factors that affect household food security status in Mojaena Wodera Woreda using both Classical and Bayesian logistic regression approaches. According to Federal Democratic Republic of Ethiopia Food Security Strategy, the recommended minimum daily intake of 2,100 kilo calorie per person per day is equivalent to 225 kilogram of grain per person per year [10].To categorize households in food secured or food insecure circumstances the total annual yield converted to Calorie and divided for household size, finally the amount of individual persons Calorie divided for the period of the study. The descriptive results show that Out of 391 observed rural households in the sample, $37.6 \%$ was food secured and $62.4 \%$ was food insecured. The average household size was 6.88 , which is large number when compared with standardized household sizes. In addition, the standard deviation of total annual yield in Quintal among households was 17.45; which indicates there is a great variation among households in total annual yields. Based on Hosmer and Lemeshow test the chi-square value and significance value shows that Classical logistic model is quite a good fit. The overall accuracy of the model to predict household food security status, in Table 6 shows that out of the 391-sample household included in the model $81.3 \%$ correctly predicted.

Using both Classical and Bayesian logistic regression analysis only eight predictors variables were statistically significant, like age of household head, marital status, farm land size, land fertility, total annual yield, improved seed used, being owner of oxen and family size. A study by Alemmeta also shows that the majority of the food insecure households were younger household heads, who own less than 1 hectare of farmlands [20]. A study by Haile also shows that age of household head, farmland size, per capita aggregate production, fertilizer application, household size, ox ownership, and educational attainment of farm households heads had a significant influence on food security. The computed partial effects at sample means using results from the logistic regression model indicated that a unit change in farmers ${ }^{\text {ee }}$ access to fertilizer or educational level of household heads or farmeres access to land or access to family planning improve the probability of food security in the study area [13].This finding is also supported by paddy reached with similar conclusion. A negative correlation between household size and food security status is expected as food requirements increase in relation to the number of persons in a household [17]. Another study by Meles, Meseret and Miruts also shows that Household family size has negative and significant influence on food security. In view of the negative impact of large family size on the food security situation, farming households should be educated on the need to adopt the family planning program so that they may bear the number of children which their resources can accommodate [21].

It is expected that households with large farms are food secure than those with small farms [18]. Animal traction power enables households to cultivate greater source of land and to execute agricultural operations timely. Therefore, a positive relationship between oxen ownership and food security expected. The higher the amount of grain food obtained from own production, the more likely the household to be food secure [13].

\section{Conclusion and Recommendation}

\subsection{Conclusion}

Achieving food security is among the most significant development challenges facing Ethiopia. It implies reaching a number of development goals, including stimulating agricultural production, increasing incomes, and improving nutrition directly at household level. To determine the response variable, household food security status a Food Balance Sheet adopted and the recommended daily calorie requirement used as a national food security line. The descriptive analysis of the study revealed that among 391 household head, $26.3 \%$ were female and $73.7 \%$ were male. The proportion of food security is higher among households led by men $(40.3 \%)$ while the proportion of food security among household led by women is small (30.1\%). Among 391 of household head $37.6 \%$ of the sample households were food secured and $62.4 \%$ were food insecured households, which fell short of the national recommended calorie requirements. By employing the forward step wise (likelihood ratio) method in SPSS and Using Bayesian approach of logistic regression analysis, eight out of twenty one predictor variables have an impact in the determining of household food security status. These significant variables were age, marital status, farm land size, land fertility, annual yield, improved seed use, having oxen and family size of household head.

\subsection{Recommendation}

In order to achieve food security, strategies designed in a way that would focus on and address the identified determinants as well as other factors that are useful to achieve household food security. Based on the results the following recommendations need to be implemented by those who are concerned.

Government and the woreda agricultural office should provide agricultural inputs to the farming households at 
affordable prices to be able to increase farmland size and total annual yield or food production. Government should provide cultivable and more fertile farm land by application of important agricultural inputs such as improved seed, an oxen and fertilizers for farmers. Education that encompasses all aspects of training and which brings about attitudinal changes targeting at reducing fertility level is important for rural households in the study area.

\section{Acronyms and Abbreviations}

$\begin{array}{ll}\text { CI } & \text { Confidence interval } \\ \text { CSA } & \text { Central Statistical Agency } \\ \text { FAO } & \text { Food and Organization } \\ \text { HFSS } & \text { Household Food Security Status } \\ \text { LR } & \text { Likelihood Ratio } \\ \text { MC } & \text { Monte Carlo } \\ \text { MCMC } & \text { Markov Chain Monte Carlo } \\ \text { SSA } & \text { Sub-Saharan African } \\ \text { SPSS } & \text { Statistical Package for the Social Sciences } \\ \text { TLU } & \text { Tropical Livestock Unit }\end{array}$

\section{References}

[1] Mustapha M., 2011. Determinants of Food Insecurity in Nigeria: Application of Binary Choice Modeling Technique.

[2] FAO. The state of food insecurity in the world. Rome, Italy.

[3] Tobin JC. Hunger effort and food security. New York: Nova Science Publishers, Inc.; 2009.

[4] FAO (2010): Food and Agricultural Organization. The State of Food Insecurity: in the world. Rome, Italy.

[5] Mitiku, A., Fufa, B., and tadesse, B., 2013. Emperical analysis of the determinant of rural Household's food security in southern Ethiopia. The case of shasheme district. Journal of agriculture science and review vol. 1, no. 6 pp. 132-138.

[6] FAO, 2009. Grassland Index. A searchable catalogue of grass and forage legumes. FAO, Rome, Italy.

[7] DFID, 2011. Department for International Development of Annual Report and Accounts 2010-11. http://www.dfid.gov.uk/Media-Room/Publications.
[8] DO Gilligan Hoddinott A S and Taffesse"An Analysis of Ethiopia's Productive Safety Net Program and Its Linkages, International Food Policy Research Institute, Washington, D.C, 2008.

[9] Fasil G. (2005). Enough with Famine in Ethiopia, Commercial printing enterprise, Addis Ababa.

[10] FDRE FSS (1996): Federal Democratic Republic of Ethiopia. Food Security Strategy, Addis Ababa, Ethiopia.

[11] Moroda, G.T., Tolossa, D. \& Semie, N. Agriculture \& Food Security (2018) 7: 65. https://doi.org/10.1186/s40066-0180217-x.

[12] Israel GD. Determining sample size. Institute of Food and Agricultural Sciences (IFAS), University of Florida; 2013.

[13] Haile, K. 2005. Causes of Household Food Insecurity in Koredegaga Peasant Association, Oromyia Zone, Ethiopia. Working Paper. University of the Free State, South Africa.

[14] Shiferaw, F., Kilmer, R., and Gladwin, C. (2003): Determinants of Food Security in Southern Ethiopia, Food Resource and Economics Department - a selected paper Presented at the 2003 American Agricultural Economics Association Meeting in Montreal, Canada.

[15] Wiley J. (2009). "An Introduction to Categorical Data Analysis" in New York.

[16] Gelman, A., Carlin, (2005). Bayesian Data Analysis, Second edition. London: CRC Pres.

[17] Paddy, 2003. Factors That Influence Food Security in Rural Households of Mount Elgon Sub County, Kenya.

[18] Rana E. Toseef A. and Mohammad U. Toseef (2009) Determinants of food security in rural areas of Pakistan, Department of Economics, The Islamia University of Bahawalpur. Pakistan.

[19] Ethiopian socio-economic survey of 2011/12 and 2013/14 data, collected by CSA of Ethiopia in collaboration with the World Bank.

[20] Alem-meta A. (2018). Determinants of food insecurity in the rural farm households in South Wollo Zone of Ethiopia: the case of the Teleyayen sub-watershed, Agricultural and Food Economics. https://doi.org/10.1186/s40100-018-0106-4.

[21] Meles T, Meseret, Miruts M (2016) Assessment of food security status and factors influencing food security in Hawi Guddina district, Ethiopia. Int Sch J 3 (3): 167-173. 